\title{
Oficinas de Aprendizagem Ativa de GNU/Linux em um Curso de Engenharia de Computação
}

\author{
Guilherme L. Wanderley ${ }^{1}$, Roberto A. Bittencourt ${ }^{1}$, Rodrigo T. Calumby ${ }^{1}$ \\ ${ }^{1}$ Universidade Estadual de Feira de Santana - Feira de Santana - Brasil \\ guilhermelw.uefs@gmail.com, roberto@uefs.br rtcalumby@uefs.br
}

\begin{abstract}
Undergraduate students majoring computer courses do not have the necessary proficiency on GNU/Linux Operating System and face dificulties migrating from Windows. This problem is found among some Universities, although not voiced enough within the communitty, albeit its significance. To solve this problem, a GNU/Linux introductory workshop based on active learning methodologies was organized to Computer Engineering undergrads. Those methodologies have proven its effectiveness on students motivation and learning, as well as on the preparatory costs for such workshop. This paper describes the preparation of the workshop, shows the methodology benefits and suggests improvements and ways of preparing relevant extra curriculum workshops.
\end{abstract}

Resumo. É frequente que estudantes de cursos de graduação em computação não possuam a proficiência necessária no Sistema Operacional GNU/Linux e enfrentem dificuldades para migração. Este problema não é devidamente sinalizado pela comunidade, apesar de sua importância. Para solucionar este problema, foi realizada uma oficina de caráter introdutório ao Sistema Operacional GNU/Linux para estudantes de Engenharia da Computação, baseada em metodologias ativas de aprendizagem. Estas metodologias foram eficazes na motivação e aprendizado dos estudantes, como também na redução dos custos de preparo da oficina. Este artigo discorre sobre preparação e realização da oficina, apresenta os benefícios da abordagem e sugere melhorias e formas de acrescentar oficinas extracurriculares relevantes em outros contextos.

\section{Introdução}

O GNU/Linux é o kernel de sistema operacional mais utilizado do mundo. Se sua adoção ainda não é forte nos computadores pessoais, todos os 500 maiores supercomputadores do mundo rodam Linux, assim como a maioria dos servidores, sistemas de segurança e a maioria dos smartphones ${ }^{1}$. Ainda assim, há uma dificuldade dos usuários, mesmo que estes sejam estudantes de cursos de tecnologia, em migrar do sistema MS Windows para o GNU/Linux. Para estes estudantes, a proficiência em GNU/Linux não só facilita seu percurso acadêmico, como também abre um leque de opções no mercado de trabalho. $O$ ensino do GNU/Linux para graduandos em Computação não parece ser um tema popular em artigos da área de computação e educação. Talvez o tema não seja percebido como um problema relevante, ou a solução seja muito custosa, ou ainda seja visto como responsabilidade do estudante buscar este conhecimento por conta própria [Santos et al. 2017].

${ }^{1}$ https: / / www. linuxfoundation.org/about/ 
VIII Congresso Brasileiro de Informática na Educação (CBIE 2019)

Anais do XXV Workshop de Informática na Escola (WIE 2019)

No curso de Engenharia da Computação da Universidade Estadual de Feira de Santana, foi constatada empiricamente a deficiência dos estudantes neste sistema operacional. Para resolver este problema, planejamos e realizamos uma oficina de GNU/Linux com os estudantes deste curso durante o segundo semestre de 2018. Esta oficina foi desenvolvida utilizando-se metodologias de aprendizagem ativa. Os resultados apontam que essas metodologias motivaram e contribuíram para a fixação dos conteúdos apresentados, assim como diminuíram os custos preparatórios de uma oficina extracurricular. Os participantes sugeriram aprimoramentos para as próximas edições e contribuíram com a comunidade, oferecendo duas oficinas posteriores durante a Semana de Integração de Engenharia da Computação.

\section{Trabalhos Relacionados}

O Sistema Operacional GNU/Linux, plataforma mais usada de software livre, encontra obstáculos para sua adoção relacionados ao medo da migração e ao desconforto com a nova interface [Alencar 2007]. Alencar et al. (2007) também sugerem que colegas podem facilitar a acomodação dos novos usuários ao novo sistema, através de peer learning. Em nosso trabalho, o uso de peer learning está relacionado à proposta de sala de aula invertida [Valente 2014]. Trevelin et al. (2013) mostram como a sala de aula invertida pode ser utilizada no Ensino Superior em cursos de tecnologia, evidenciando também o sucesso obtido pela metodologia ao compará-la com uma abordagem tradicional.

O trabalho mais próximo deste artigo é o de Santos et al. (2017). Neste, relatase o desenvolvimento de uma oficina para ensino de GNU/Linux para estudantes de computação de modo similar a nosso trabalho. No entanto, diferente de nossa oficina, o trabalho citado adota uma metodologia de aulas expositivas em uma oficina de seis horas de duração. São cobertos apenas os conteúdos de história do software livre, comandos básicos do terminal GNU/Linux e programas para o auxilio de programação no GNU/Linux. Nossa oficina utiliza uma metodologia de aprendizagem ativa com carga horária de 24 horas, além de abordar conteúdo mais abrangente.

\section{Metodologia}

O objetivo da oficina foi preencher a lacuna na formação dos estudantes, capacitandoos a utilizar o GNU/Linux, bem como qualificando-os a fazer a prova de certificação aplicada pelo Linux Professional Institute (LPI - Exam 101). A oficina ocorreu durante o segundo semestre de 2018, com um total de 24 horas de carga horária distribuída em 12 encontros de 2 horas. Os encontros foram realizados no Laboratório de Programação e cada estudante realizou as atividades em uma máquina com a distribuição Linux Mint. Os participantes eram estudantes de Engenharia da Computação de variados semestres que compareceram de forma voluntária. Ao longo da oficina, 37 alunos compareceram aos encontros. Ao final da oficina, apenas 10 deles obtiveram frequência igual ou superior a $75 \%$. A média de presença foi de aproximadamente 12 estudantes por encontro.

A metodologia buscou motivar os estudantes, tendo caráter prático e colaborativo. Cada encontro tinha duas etapas: na primeira, o estudante organizador apresentava o tema; na segunda, um grupo de três participantes se responsabilizava por um assunto: um participante realizava a apresentação teórica, outro fazia apresentação prática do tema e o terceiro preparava um exercício prático. Pelo cronograma da oficina, três participantes 
VIII Congresso Brasileiro de Informática na Educação (CBIE 2019)

Anais do XXV Workshop de Informática na Escola (WIE 2019)

se voluntariavam para realizar as atividades de um encontro. Em geral, este agendamento ocorria duas semanas antes da apresentação do conteúdo. O cronograma foi proposto com base no curso de GNU/Linux da Linux Foundation na plataforma online $e d X$. Foram realizadas algumas adaptações a fim de que sempre houvesse um conteúdo prático nos encontros, que são descritos a seguir.

Dia 1 - Apresentação da oficina (conteúdo e metologia); Dia 2 - Acesso ao sistema e busca de informações: comandos de login e desligamento, terminais e comandos para criar, localizar, copiar e remover arquivos; Dia 3 - Ambientes de desktop, pipeline e arquivos no terminal: exposição dos ambientes desktop mais comuns, comandos cat, head, tail, less e combinação usando pipe; Dia 4 - Processos e árvore do sistema: comandos ps, top, cron, free, syslog, dmesg e kill e conteúdo do diretório root; Dia 5 - Repositórios: o que são, como criar e qual seu conteúdo e gerenciadores de pacotes (dpkg); Dia 6 - Licenças de software, tipos de arquivos, compressão e backup: principais licenças e comandos diff3, patch, file, tar, gzip e bz2; Dia 7 - Editores de texto, variáveis de ambiente e shell: editores nano e vi, user environment, variável PATH e o shell; Dia 8 - Exercícios de revisão, usuários, grupos e permissões de arquivos: comandos sudo, root, who e whoami; Dia 9 - Manipulação de arquivos: comandos sort, cut, awk e sed; Dia 10 - funcionamento das redes em Linux e configuração: os principais arquivos para configurar uma rede; Dia 11 - Shell Script: status de saída, argumentos, variáveis de ambiente, funções, manipulação de strings e calculadora; Dia 12 - Simulado e questionários finais: simulado com base no Exame LPI 101 e questionários de avaliação da oficina.

Nos primeiros encontros, foram ensinados os programas básicos e o nível de dificuldade foi progredindo à medida que novos conceitos e ferramentas eram expostas. No décimo encontro, a dinâmica foi diferente. Foi convidado um professor de outra instituição de ensino para apresentar e demonstrar conteúdos de configuração de rede. Este encontro foi apenas expositivo, tendo o professor explicado conceitos e demonstrado a construção prática de uma rede. No último encontro foi realizado um simulado com base no exame 101 do Linux Professional Institute.

Todos os participantes responderam a três questionários. O questionário que antecedeu a oficina avaliou a familiaridade dos participantes com comandos básicos. $\mathrm{O}$ mesmo foi novamente aplicado ao término da oficina, para mensurar a evolução dos participantes. Ao final, também foi aplicado um questionário de avaliação da própria oficina.

\section{Nossa Experiência}

O primeiro encontro foi dirigido pelo professor e pelo aluno organizador. Neste encontro, explicou-se o formato da oficina, história do software livre e do GNU/Linux e comandos básicos no terminal. Ao final, foram definidos trios de estudantes responsáveis pelos encontros seguintes. A partir daí, os encontros foram dirigidos pelos participantes da oficina, excetuando-se alguns conceitos teóricos ministradas pelo aluno organizador.

Em geral, os participantes não apresentavam muitas dúvidas durante a explicação das ferramentas ou as demonstrações práticas. As dúvidas surgiam durante a atividade prática, o que pode indicar uma falsa sensação de entendimento durante a explicação e a timidez em interromper a explicação. De toda forma, as dúvidas foram vistas como um aspecto positivo da parte prática. Elas foram respondidas visando desenvolver a autonomia dos participantes em relação ao uso do sistema. 
VIII Congresso Brasileiro de Informática na Educação (CBIE 2019)

Anais do XXV Workshop de Informática na Escola (WIE 2019)

Parte do sétimo encontro foi sobre editores de texto. Após uma rápida demonstração do editor nano, foi utilizado um tutorial já pronto para o editor vim, o vimtutor. Este tutorial consiste em um texto a ser editado dentro do próprio programa, sem necessidade de explicações prévias. Isto foi citado como um aspecto positivo na avaliação pós-oficina: "Achei ele muito útil, substituindo o auxílio de alguém que tire dúvidas quase que completamente, além de evitar o constrangimento de repetir a mesma dúvida várias vezes...". Apesar do relato anterior, isto não inibiu os estudantes a questionarem e tirarem suas dúvidas. A quantidade de dúvidas nesta prática foi bastante similar aos outros encontros. No penúltimo encontro, sobre shell script, houve reclamações sobre a duração. Por ser um conteúdo vasto, motivou comentários como: "Melhorar a gestão de tempo. Diminuir a quantidade de assuntos quando o conteúdo da aula é extenso".

\subsection{Avaliação}

Ao final da oficina, os participantes responderam a um questionário. As respostas apontaram para um crescimento do conhecimento acerca do sistema operacional. Embora nenhum participante tenha avaliado seu conhecimento após a oficina com a nota máxima, isto é visto como um aspecto positivo. Significa que foram expostos a conteúdos suficientes para perceber o quanto ainda têm a aprender. As respostas à pergunta "quão úteis serão estes novos conhecimentos ao longo da sua carreira profissional e/ou vida acadêmica?" demonstram que os participantes percebem o conteúdo como útil. Outras questões buscaram avaliar a metodologia empregada e o resultado foi positivo. Isto também se refletiu no espaço aberto para comentários: "A prática é um aspecto muito positivo da oficina" e "A metodologia é ótima pois envolve muito mais os alunos, incentivando a aprender mais". O único comentário negativo foi "Como a oficina é feita por nós, algumas apresentações ficaram um pouco a desejar". Ainda assim, este mesmo participante escreveu no campo aberto: "Pra mim, foi a melhor coisa desse semestre :D".

Ademais, no espaço para comentários, os participantes manifestaram o desejo por exercícios de revisão e pequenas avaliações parciais. Estes são dois comentários representativos: "Passar pequenas atividades ao longo da oficina ou fazer pequenos simulados" e "Aspectos negativos: falta de avaliações rápidas para revisar o conhecimento adquirido". Um outro resultado da oficina foi a colaboração dos participantes em oficinas posteriores. Foram ofertadas duas oficinas de GNU/Linux durante a Semana de Integração de Engenharia da Computação na instituição: uma básica (conceitos iniciais e terminal) e outra avançada (programas mais avançados do sistema). Estas oficinas foram organizadas pelo mesmo aluno e professor com auxílio dos participantes da oficina original. Além disto, foram estes participantes que ministraram as oficinas.

\section{Lições Aprendidas}

Sala de aula invertida funcionou bem. Os participantes avaliaram positivamente o ato de preparar e apresentar o conteúdo dos encontros, com comentários como: "bom ter que dar algumas aulas, motiva a gente a ter que estudar para poder ensinar".

O processo de peer learning forneceu diferentes perspectivas e amenizou a carga horária semanal necessária para os participantes. Os estudantes relataram que, ao fazer o trabalho em trio, a carga horária requerida pela oficina foi baixa, o que ajudou a conciliar com as disciplinas formais do curso de graduação. 
VIII Congresso Brasileiro de Informática na Educação (CBIE 2019)

Anais do XXV Workshop de Informática na Escola (WIE 2019)

Atividades práticas motivaram e ajudaram a consolidar os conteúdos aprendidos. Os estudantes demonstraram satisfação pelos conteúdos aprendidos na prática. Ainda assim, houve reclamação sobre a ausência de alguns assuntos teóricos e algumas ferramentas, que, devido à sua extensão, não foram cobertos.

Mesmo com atividades práticas, estudantes sentem a necessidade de revisão. Ainda que os estudantes tenham considerado a prática como aspecto positivo, em geral concordaram na necessidade em exercícios de revisão do conteúdo.

O conteúdo da oficina é relevante para estudantes de Engenharia da Computação e não há aulas formais para cobrir os assuntos. Os estudantes avaliaram o conteúdo como bastante relevante às atividades acadêmicas e profissionais. No entanto, tanto a universidade em que ocorreu esta oficina como outras instituições não possuem, na matriz curricular, um espaço formal para cobrir estes assuntos.

É possível desenvolver uma oficina relevante com um custo de preparação menor do que uma disciplina da grade curricular formal. Devido à metodologia adotada, a preparação de materiais a serem apresentados pelos organizadores é diminuída, a aprendizagem dos estudantes é estimulada e os conteúdos são cobertos satisfatoriamente.

\section{Conclusões}

Este artigo descreveu uma oficina de GNU/Linux que foi organizada no intuito cobrir conteúdos que são fundamentais para instrumentalizar a vida acadêmica e profissional de estudantes de Computação. A metodologia definida para esta oficina pode ser reproduzida para outras em diferentes temas. Esta consistiu de sala de aula invertida e peer learning, na qual um trio de alunos preparou apresentação teórica, demonstração e atividade prática das ferramentas. A metodologia engajou os participantes, sendo avaliada positivamente por estes, bem como permitiu diminuir o tempo de preparação do material por parte dos organizadores da oficina, viabilizando oficinas para cobrir conteúdos não abordados na estrutura curricular formal de um curso de graduação em computação. Através de questionários e depoimentos presenciais, foi constatada a eficácia da metodologia. No futuro, pretende-se estudar como a metodologia impacta na motivação, mensurada através do modelo ARCS, além de implementar as modificações sugeridas pelos alunos.

\section{Referências}

Alencar, A. F. (2007). A pedagogia da migração do software proprietário para o livre: uma perspectiva freiriana. Produção de terceiros sobre Paulo Freire; Série Dissertações.

Santos, A. C. T., Melo, B. K. A. S., Lima, D. F. S., Dantas, D. V., Santos, I. N., Silva, M. H. A., Praxedes, M. M. R., Silva, P. R., et al. (2017). Workshop de gnu/linux: incentivando o uso de softwares livres nos cursos de informática. In $25^{\circ}$ Workshop sobre Educação em Computação (WEI 2017), volume 25. SBC.

Trevelin, A. T. C., Pereira, M. A. A., and de Oliveira Neto, J. D. (2013). A utilização da "sala de aula invertida" em cursos superiores de tecnologia: comparação entre o modelo tradicional e o modelo invertido "flipped classroom" adaptado aos estilos de aprendizagem. Revista de estilos de aprendizaje, 6(12).

Valente, J. A. (2014). Blended learning e as mudanças no ensino superior: a proposta da sala de aula invertida. Educar em Revista, (4):79-97. 